\title{
Post Operative Acute Kidney Injury in Gastro Intestinal and Hepatobiliary Surgery in a Tertiary Centre in Western India - A Retrospective Analysis
}

\author{
Dr.Bhavin B Vasavada, \\ Consultant Hepatobiliary and liver transplant surgeon, \\ Shalby hospitals, \\ Ahmedabad- 380015 \\ India. \\ Email: drbhavin.liversurgeon@gmail.com \\ Dr.Hardik Patel. \\ Consultant Hepatobiliary and liver transplant surgeon, \\ Shalby hospitals, \\ Ahmedabad- 380015 \\ India \\ Conflict of interests: none \\ Funding: No \\ Ethical clearance: obtained from hospital ethical committee. \\ Abbreviations: American society of anaesthesiology (ASA), Acute Kidney Injury \\ Network (AKIN), Risk Injury Failure Loss, End stage (RIFLE)
}

\author{
ABSTRACT: \\ AIM: \\ Aim of our study was to evaluate incidence and causative factors for acute kidney \\ injury in gastrointestinal and hepatobiliary surgeries.
}

Material and methods:

All the gastrointestinal surgeries performed between April 2018 to March 2020, in our institution have been analysed for acute kidney injury. Acute kidney injury defined according to acute kidney injury network classification. Categorical variables were evaluated by chi square test and continuous variables by Mann Whitney U test. Statistical analysis was done using SPSS version 23. $\mathrm{P}<0.05$ was considered significant

Results:

We performed 331 gastrointestinal and hepatobiliary surgery from April 2018 to March 2020. After exclusion 317 patients were included in study population.14 patients $(4.4 \%)$ were defined as having acute kidney injury according to acute kidney injury network classifications. On univariate analysis acute kidney injury was associated with open surgery $(\mathrm{p}=0.002$, Intra operative hypotension $(\mathrm{p}=0.006)$, CDC grade of surgery $(p<0.001)$, increased used to blood products $(p=0.004)$, higher ASA grade $(p<0.0001)$, increased operative time $(p<0.0001)$. On multivariate logistic regression analysis higher ASA grade $(\mathrm{p}=0.001)$ and increased operative time $(0.015)$ independently predicted acute kidney injury. Acute kidney injury was also significantly associated with 90 days mortality. $(\mathrm{p}=<0.0001)$

Conclusion:

Post-operative acute kidney injury was associated with significant mortality in gastrointestinal and hepatobiliary surgery. Open surgery, higher CDC grade surgery, more blood products, higher ASA grades, increase operative time predicted acute 
kidney injury in post operative periods. Higher ASA grades and increased operative time predicted acute kidney injury.

Key words: Acute Kidney Injury; Gastrointestinal surgery; HPB surgery; perioperative care; critical care.

\section{Background:}

Post Operative Acute kidney injury is a one of the very common post-operative complications [1]. Many studies have shown that post-operative acute kidney injury is associated with other morbidities and mortalities. [2,3,4,5].

Very few studies has evaluated risk of acute kidney injury in combine cohort of gastrointestinal and hepatobiliary surgery.

Aim of the study:

Aim of this study was to evaluate incidence and risk factors of acute kidney injury retrospectively from our data of gastrointestinal and hepatobiliary surgery.

Material and Methods:

\section{Sample size calculation:}

Sample size required for prospective analysis determined by keeping margin of error by $5 \%$, (alpha error) and power of study 80 percent (1-beta) and prevlance of Acute kidney injury in gastrointestinal and hepatobiliary surgery can be up to 35 percent as per published literature. [8,9].We presumed acute kidney injury rate on higher side based on literature. Our analysis of our data showed around 5\% aki incidence in our data. We calculated 14 patients will be needed for the study in AKI group.

\section{Inclusion crteria:}

All patient who underwent gastrointestinal and hepatobiliary surgeries.

\section{Exclusion crteria:}

- Patients who had acute kidney injury pre operatively

- Patients who were on dialysis before surgery

- Patients who died on post operative day 1, before Acute Kidney Injury criteria is fulfilled.

All the gastrointestinal surgeries performed from April 2018 to June 2019 in our institution have been analysed for acute kidney injury.

\section{Acute kidney injury definition:}

Acute kidney injury defined according to acute kidney injury network classification. [6,7]. Any grade of acute kidney injury was considered significant.

Pre operative and Intra operative factors were analysed for development of acute kidney injury.

\section{Statistical analysis:}

Analysis of means or medians were selected according to skewness and standard error of skeuness and kurtosis and standard error of kurtosis analysis.Catagorical 
variants were analysed using chi square test or fisher t test where ever appropriate. Continuous variable were analysed using Mann whitney u test.

$P$ value less than 0.05 was considered significant. Multivariate analysis was done using logistic regression method. SPSS (IBM) version 23 was used for statistical analysis.

We also prepared Kaplan Meier survival curve with log rank analysis to compare 90 days survival rates in patients with or without AKI.

\section{Results:}

We performed 333 gastrointestinal and hepatobiliary surgery from April 2018 to March 2020. 10 patients had pre operative acute kidney injury, 4 patients were on dialysis and one patient died on post operative day 0 and hence excluded from the study. [figure 2].

318 patients were included in the study. 14 patients (4.4\%) was defined as having acute kidney injury according to acute kidney injury network classifications. [6,7].

On univariate analysis acute kidney injury was associated with open surgery $(\mathrm{p}=$ $0.002)$, Intra operative hypotension $(\mathrm{p}=0.006)$, CDC grade of surgery $(\mathrm{p}<0.001)$ [8] , increased used to blood products $(\mathrm{p}=0.004)$,higher ASA grade $(\mathrm{p}<0.0001)$, increased operative time $(\mathrm{p}<0.0001)$.

On multivariate logistic regression analysis higher ASA grade $(\mathrm{p}=0.001$, odds ratio 13.87, 95\% confidence interval 2.99-64.29) and increased operative time ( $\mathrm{p}=0.015$, odds ratio $1.008,95 \%$ confidence interval $1.002-1.014$ ) independently predicted acute kidney injury. [Table 2]

Acute kidney injury was also significantly associated with 90 days mortality. ( $\mathrm{p}=$ $<0.0001$ )

On Kaplan Meier survival analysis patients with acute kidney injury had significantly less 90 days survival than patients without acute kidney injury. [Figure 1]

Overall median hospital stay was also significantly longer for patent with acute kidney injury than without it (median 2 days vs. 4.5 days)

\section{DISCUSSION:}

Acute kidney injury (AKI) is a common complication in patients undergoing major Gastrointestinal and hepatobiliary surgery. Various studies stated, incidence of AKI after major abdominal surgery may go up to $35 \%$. Several patient-related, procedurerelated factors for AKI. AKI was associated with increase incidence of morbidity and mortality in various studies. [8,9]

Aim of our study was to evaluate incidence and various factors associated with Acute kidney injury. Two criteria for diagnosing acute kidney injury is widely used one is RIFLE criteria and other is Acute Kidney Injury Network criteria. [6,10]. We used Acute Kidney Injury Network criteria to diagnose acute kidney injury network and we included all the grades of acute kidney injury network classification in our analysis. [Figure 2]

Overall incidence of acute kidney injury in our cohort was $4.1 \%$. Cho et al. reported 7.6 percent acute kidney injury after HPB surgeries. [9] Meersch et al. reported high 
incidence of acute kidney injury.

Acute kidney injury in our study was significantly associated with mortality. Literature also shows that acute kidney injury is associated with high mortality. $[9,10,11,12,13]$.

On univariate analysis in our study open surgeries, intraoperative hypotension, higher ASA (American society of anaesthesiology) grade, higher CDC wound grade, increase blood product requirement, and increased operative time were associated with development of acute kidney injury. Hobson et al. studied various risk factors associated with peri operative risk factors, and shoed previous history of chronic kidney disease and haemoglobin level was associated with post operative acute kidney injury. [14] In our study increase blood product required was associated with acute kidney injury. Lim et al. suggested that hepatectomy was associated with high incidence of acute kidney injury, they suggested major hepatectomy, increase meld score, advanced age and prolonged operative duration were associated with acute kidney injury. In our study type of surgery (HPB or LUMINAL) and age were not associated with acute kidney injury however prolonged operative duration was associated with acute kidney injury in our study also.[15]

Various studies showed that intra operative hypotension was associated with post operative acute kidney injury.[16,17,18] In our study also intraoperative hypotension was associated with acute kidney injury in univariate analysis however it did not independently predicted acute kidney injury on multivariate analysis.

In multivariate analysis in our study higher American society of anaesthesiology score $(\mathrm{p}<0.001)$, and increased operative time $(\mathrm{p}=0.015)$ were associated with acute kidney injury Literature also supports these findings. [19,20]

In our study acute kidney injury was associated with increased hospital stay which is also supported by literature. [21,22]

Being a retrospective analysis our study has inherent limitations associated with retrospective studies. Number of patients who developed acute kidney injury were low in our studies. More studies with higher number of patients is required to confirm our findings.

In conclusion, post-operative acute kidney injury was associated with significant mortality in gastrointestinal and hepatobiliary surgery. Open surgery, higher CDC grade surgery, more blood products, higher ASA grades, increase operative time predicted acute kidney injury in post operative periods. Higher ASA grades and increased operative time independently predicted acute kidney injury.

\section{Refrences:}

1. Park JT. Postoperative acute kidney injury. Korean J Anesthesiol. 2017 Jun;70(3):258-266.

2. Chertow GM, Levy EM, Hammermeister KE, Grover F, Daley J. Independent association between acute renal failure and mortality following cardiac surgery. Am J Med. 1998;104:343-348.

3. Mangano CM, Diamondstone LS, Ramsay JG, Aggarwal A, Herskowitz A, Mangano DT. Renal dysfunction after myocardial revascularization: risk factors, adverse outcomes, and hospital resource utilization. The Multicenter Study of Perioperative Ischemia Research Group. Ann Intern Med. 1998;128:194-203. 
4. Thakar CV, Liangos O, Yared JP, Nelson D, Piedmonte MR, Hariachar S, et al. ARF after open-heart surgery: Influence of gender and race. Am J Kidney Dis. 2003;41:742-751.

5. Biteker M, Dayan A, Tekkeşin Aİ, Can MM, Taycı İ, İlhan E, et al. Incidence, risk factors, and outcomes of perioperative acute kidney injury in noncardiac and nonvascular surgery. Am J Surg. 2014;207:53-59.

6. Mehta RL, Kellum JA, Shah SV, et al. Acute Kidney Injury Network: report of an initiative to improve outcomes in acute kidney injury. Crit Care. 2007;11(2):R31.

7. Kellum JA. Diagnostic Criteria for Acute Kidney Injury: Present and Future. Crit Care Clin. 2015;31(4):621-632. doi:10.1016/j.ccc.2015.06.001

8. Surgical Site Infection (SSI) Event: Center for Disease Control. 2010. http://www.cdc.gov/nhsn/PDFs/pscManual/9pscSSIcurrent.pdf?agree=y es\&next=Accept. Updated January 2015. Accessed March 3, 2015.

9. Cho E, Kim SC, Kim MG, Jo SK, Cho WY, Kim HK. The incidence and risk factors of acute kidney injury after hepatobiliary surgery: a prospective observational study. BMC Nephrol. 2014;15:169.

10. Bellomo R, Ronco C, Kellum JA, Mehta RL, Palevsky P: Acute Dialysis Quality Initiative workgroup: acute renal failure - definition, outcome measures, animal models, fluid therapy and information technology needs: the Second International Consensus Conference of the Acute Dialysis Quality Initiative (ADQI) Group. Crit Care 2004, 8: R204-R212.

11. Meersch, Melanie MD; Schmidt, Christoph MD; Zarbock, Alexander MD Perioperative Acute Kidney Injury: An Under-Recognized Problem, Anesthesia \& Analgesia: October 2017 - Volume 125 - Issue 4 - p 1223-1232

12. Lei VJ, Luong T, Shan E, et al. Risk Stratification for Postoperative Acute Kidney Injury in Major Noncardiac Surgery Using Preoperative and Intraoperative Data. JAMA Netw Open. 2019;2(12):e1916921.

13. Kim CS, Oak CY, Kim HY, et al. Incidence, predictive factors, and clinical outcomes of acute kidney injury after gastric surgery for gastric cancer. PLoS ONE. 2013;8:e82289. doi: 10.1371/journal.pone.0082289.

14. Hobson C, Ruchi R, Bihorac A. Perioperative Acute Kidney Injury: Risk Factors and Predictive Strategies. Crit Care Clin. 2017;33(2):379-396.

15. Lim C, Audureau E, Salloum C, et al. Acute kidney injury following hepatectomy for hepatocellular carcinoma: incidence, risk factors and prognostic value. HPB (Oxford). 2016;18(6):540-548.

16. Hallqvist L, Granath F, Huldt E, Bell M. Intraoperative hypotension is associated with acute kidney injury in noncardiac surgery: An observational study. Eur J Anaesthesiol. 2018;35(4):273-279.

17. Sun LY, Wijeysundera DN, Tait GA, Beattie WS. Association of intraoperative hypotension with acute kidney injury after elective noncardiac surgery. Anesthesiology. 2015;123(3):515-523.

18. Onuigbo MA, Agbasi N. Intraoperative hypotension - a neglected causative factor in hospital-acquired acute kidney injury; a Mayo Clinic Health System experience revisited. J Renal Inj Prev. 2015;4(3):61-67. Published 2015.

19. Abelha FJ, Botelho M, Fernandes V, Barros H. Determinants of postoperative acute kidney injury. Crit Care. 2009;13(3):R79.

20. Long TE, Helgason D, Helgadottir S, et al. Acute Kidney Injury After Abdominal Surgery: Incidence, Risk Factors, and Outcome. Anesth Analg. 2016;122(6):1912-1920. 
21. Causey MW, Maykel JA, Hatch Q, Miller S, Steele SR. Identifying risk factors for renal failure and myocardial infarction following colorectal surgery. J Surg Res. 2011;170:32-37.

22. Lee EH, Kim HR, Baek SH, et al. Risk factors of postoperative acute kidney injury in patients undergoing esophageal cancer surgery. J Cardiothorac Vasc Anesth. 2014;28:948-954.

\begin{tabular}{|c|c|c|c|}
\hline FACTORS & $\begin{array}{lr}\text { ACUTE } & \text { KIDNEY } \\
\text { INJURY } & \text { (AKI) } \\
(\mathrm{N}=13) & \end{array}$ & $\begin{array}{lr}\text { NO } & \text { ACUTE } \\
\text { KIDNEY } & \text { INJURY } \\
(\mathrm{N}=304) & \\
\end{array}$ & P VALUE \\
\hline $\begin{array}{l}\text { AGE } \\
\text { (Median/range) }\end{array}$ & $61.5 /(34-80)$ & $54 /(7-80)$ & 0.058 \\
\hline $\begin{array}{ll}\text { SEX } & (\mathrm{M} / \mathrm{F}) \\
(189 / 142) & \end{array}$ & $(7 / 6)$ & $180 / 124$ & 0.148 \\
\hline $\begin{array}{l}\text { Intra Operative } \\
\text { hypotension }(n=23)\end{array}$ & 4 & 15 & 0.006 \\
\hline $\begin{array}{l}\text { Emergency } \\
\text { Surgeries }(n=60)\end{array}$ & 5 & 49 & 0.06 \\
\hline Hpb Surgery (177) & 8 & 169 & 0.767 \\
\hline $\begin{array}{lr}\text { Luminal } & \text { surgeries } \\
\text { (upper } & \text { gi,small } \\
\text { bowel } & \text { and } \\
\text { colorectal) } & (98)\end{array}$ & 3 & 95 & 0.657 \\
\hline $\begin{array}{l}\text { OPERATIVE } \\
\text { TIME } \\
\text { (Median/range) }\end{array}$ & $180(60-600)$ & $90(15-800)$ & $<0.0001$ \\
\hline ASA (Mean/range) & $3.5(2-4)$ & $2.00 /(1-4)$ & $<0.0001$ \\
\hline $\begin{array}{l}\text { BLOOD } \\
\text { PRODUCT } \\
(\text { Mean/sd) } \\
(0.00 / 3.821)\end{array}$ & $1.0 /(0-15)$ & $0.00 /(0-40)$ & 0.004 \\
\hline $\begin{array}{ll}\text { GRADE } & \text { OF } \\
\text { SURGERY } & \\
\text { (median/range) } & \end{array}$ & $3.0 /(2-4)$ & $2.0 /(1-4)$ & 0.002 \\
\hline $\begin{array}{l}\text { Open } \\
(\mathrm{n}=171)\end{array}$ & 13 & 158 & 0.002 \\
\hline
\end{tabular}

TABLE: 1 UNIVARIATE ANALYSIS OF ACUTE KIDNEY INJURY. 
TABLE:2 MULTIVARIATE ANALYSIS OF ACUTE KIDNEY INJURY

\begin{tabular}{|l|l|l|l|}
\hline Factor & P value & Odds ratio & $\begin{array}{l}95 \% \text { confidence } \\
\text { interval }\end{array}$ \\
\hline Blood products & 0.114 & 0.74 & $0.50-1.07$ \\
\hline ASA & 0.001 & 13.87 & $2.99-64.29$ \\
\hline Operative time & 0.015 & 1.008 & $1.002-1.014$ \\
\hline Open Surgery & 0.340 & 3.51 & $0.26-46.44$ \\
\hline Grade of surgery & 0.321 & 0.51 & $0.135-1.92$ \\
\hline $\begin{array}{l}\text { Intra operative } \\
\text { Hypotension }\end{array}$ & 0.415 & 0.46 & $0.074-2.91$ \\
\hline
\end{tabular}

\section{Overall Comparisons}

\begin{tabular}{|l|c|c|c|}
\hline & Chi-Square & df & Sig. \\
\hline $\begin{array}{l}\text { Log Rank } \\
\text { (Mantel-Cox) }\end{array}$ & 161.105 & 1 & .000 \\
\hline
\end{tabular}

The vector of trend weights is $-1,1$. This is the default.

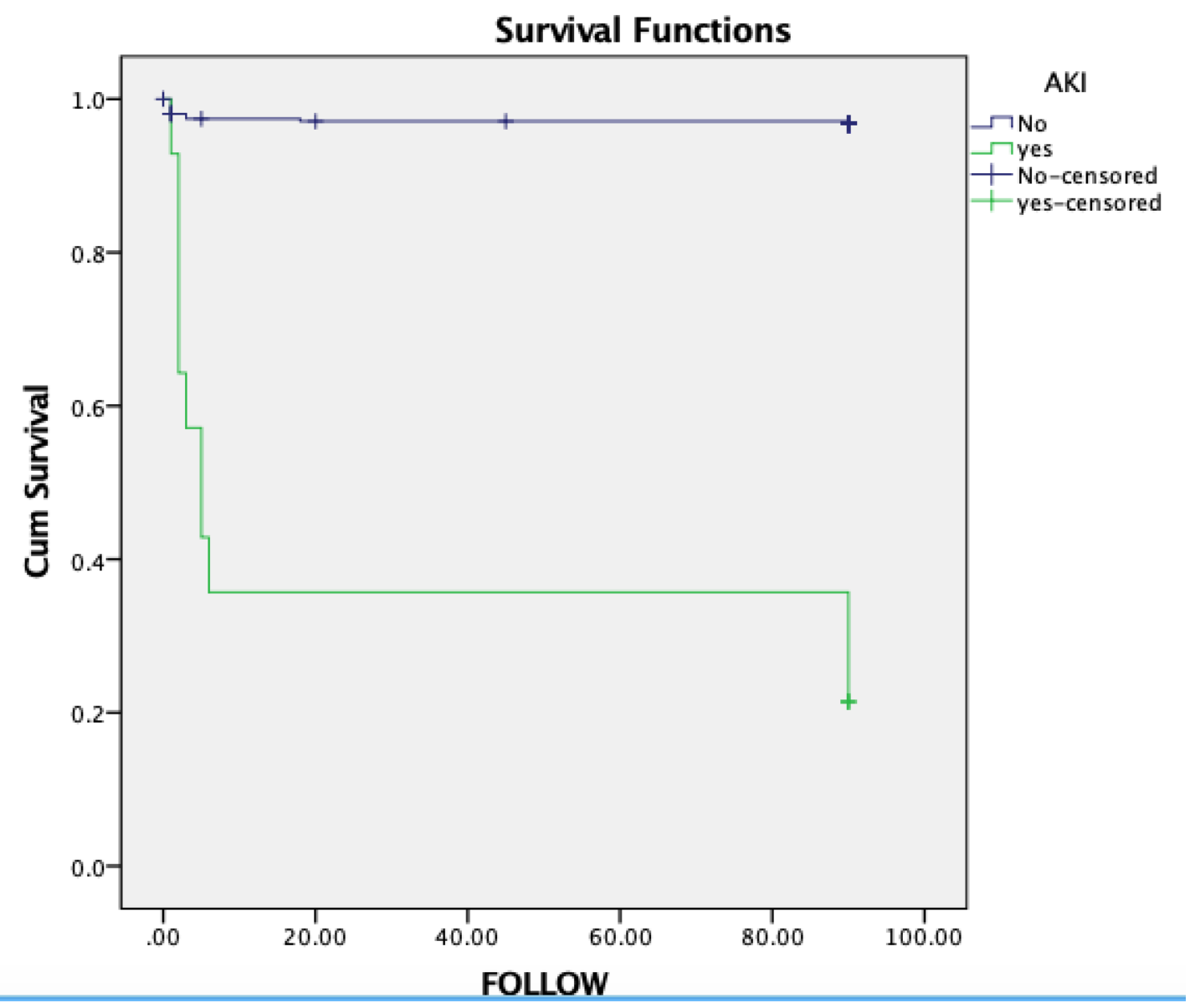

Figure:1 Kaplan meier survival analysis showed 90 days survival was sginificantly less in patient who developed acute kidney injury. 


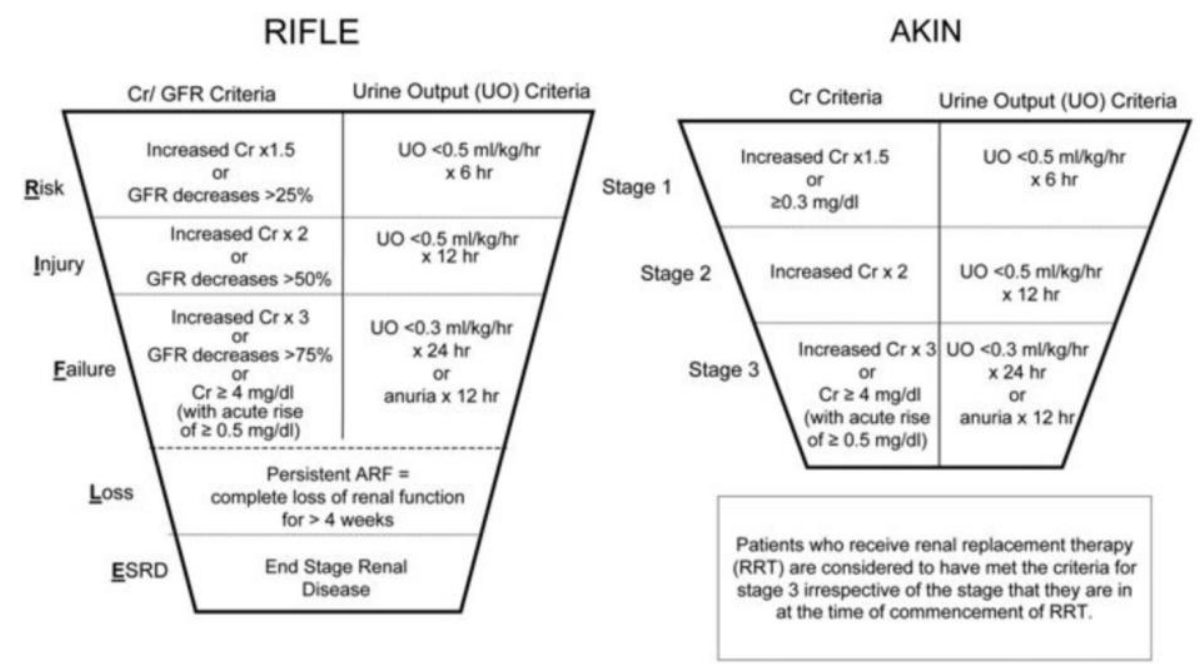

Figure 2. RIFLE and AKIN classifications for acute kidney injury. Risk-InjuryFailure-Loss-Endstage renal disease (RIFLE) and Acute Kidney Injury Network (AKIN) classifications for acute kidney injury (adapted from $[6,10]$ 